DOI: https://doi.org/10.47405/mjssh.v6i1.623

\begin{tabular}{|c|c|}
\hline 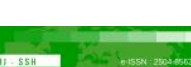 & Malaysian Journal of Social Sciences and Humanities (MJSSH) \\
\hline Malaysian Journal of & Volume 6, Issue 1, January 2021 \\
\hline (MJ-ssH) & e-ISSN : 2504-8562 \\
\hline & $\begin{array}{l}\text { Journal home page: } \\
\text { www.msocialsciences.com }\end{array}$ \\
\hline
\end{tabular}

\title{
Sorotan Literatur Bersistematik: Komponen Efikasi Kendiri dalam Pendidikan Matematik
}

\author{
Noraida Md Idrus ${ }^{1}$, Siti Mistima Maat ${ }^{1}$ \\ ${ }^{1}$ Fakulti Pendidikan, Universiti Kebangsaan Malaysia (UKM) \\ Correspondence: Noraida Md Idrus (noraida.idrus@moe.gov.my)
}

\begin{abstract}
Abstrak
Persaingan yang sihat dalam bidang pendidikan menjadikan setiap individu berusaha untuk meningkatkan kebolehan dan kompetensi dalam aspek pengetahuan, kemahiran dan nilai berkaitan matematik. Matematik sebagai suatu alat komunikasi yang penting dalam mengejar kemajuan era Revolusi Industri 4.0 memerlukan komuniti yang fasih dan berliterasi matematik. Fokus utama untuk melahirkan generasi pemimpin yang berpemikiran analitikal, kritikal dan logik menggesa sektor pendidikan mengenal pasti isu dan kepincangan efikasi kendiri berkaitan matematik daripada peringkat akar umbi. Tujuan kajian ini dijalankan adalah untuk membuat tinjauan literatur bersistematik terhadap komponen efikasi kendiri dan rangkumannya dalam penyelidikan pendidikan matematik. Dua persoalan kajian yang diberi penekanan ialah komponen efikasi kendiri dan bagaimana efikasi kendiri dikaji dalam penyelidikan empirikal pendidikan matematik. Kajian ini menggunakan Model PRISMA. Dua enjin carian digunakan iaitu Education Resources Information Centre (ERIC) dan Google Scholar. Daripada 152 artikel yang dikenal pasti, sebanyak 20 artikel diterima yang memenuhi tujuan kajian. Berdasarkan analisis yang dijalankan, terdapat 4 komponen efikasi kendiri yang telah dikenal pasti iaitu efikasi kendiri matematik, efikasi kendiri teknologi, efikasi kendiri akademik dan efikasi kendiri pengajaran. Dapatan juga menunjukkan majoriti kajian efikasi kendiri dijalankan secara kuantitatif berbanding dengan kualitatif. Garis penyelidikan utama yang diperhatikan ialah tahap efikasi kendiri, hubungan antara efikasi kendiri dengan pemboleh ubah lain yang berkaitan, dan pembangunan efikasi kendiri. Walaupun banyak kajian lepas dijalankan di benua Asia, namun begitu jumlah kajian yang menekankan efikasi kendiri dalam persekitaran Malaysia masih dikategorikan sedikit. Justeru hasil kajian ini diharapkan dapat memberikan kefahaman yang mendalam agar kajian sebegini boleh dilaksanakan dalam konteks pendidikan di Malaysia.
\end{abstract}

Kata kunci: efikasi kendiri matematik, efikasi kendiri, matematik, sorotan literatur

\section{Systematic Literature Review: Components of Self-efficacy in Mathematics Education}

\begin{abstract}
Healthy competition in the field of education makes every individual strive to improve their abilities and competencies in terms of knowledge, skills and values related to mathematics. Mathematics as an important communication tool in the pursuit of the progress of the Industrial Revolution 4.0 era requires a community that is fluent and literate in mathematics. The main focus is to produce a generation of leaders who are analytical, critical and logical thinking urging the education sector to identify issues and shortcomings of self-efficacy related to mathematics from the grassroots level. The
\end{abstract}


purpose of this study is to make a systematic literature review on the components of self-efficacy and its inclusion in mathematics education research. Two research questions that are emphasised are the components of self-efficacy and how self-efficacy is studied in empirical research in mathematics education. This study uses the PRISMA Model. Two search engines are used, namely the Education Resources Information Center (ERIC) and Google Scholar. Out of the 152 articles identified, a total of 20 articles were accepted that met the purpose of the study. Based on the analysis conducted, there are 4 components of self-efficacy that have been identified, namely mathematical self-efficacy, technological self-efficacy, academic self-efficacy and teaching self-efficacy. The findings also show that the majority of self-efficacy studies are conducted quantitatively compared to qualitatively. The main research lines observed were the level of self-efficacy, the relationship between self-efficacy and other relevant variables, and the development of self-efficacy. Although many previous studies have been conducted in the Asian continent, the number of studies that emphasise self-efficacy in the Malaysian environment is still considered small. Therefore, the results of this study are expected to provide a deep understanding so that such studies can be implemented in the context of education in Malaysia.

Keywords: mathematical self-efficacy, self-efficacy, mathematics, literature review

\section{Pengenalan}

Matematik merupakan mata pelajaran asas yang perlu dipelajari dalam sistem persekolahan di kebanyakan negara di dunia termasuk di Malaysia. Matematik yang sering dianggap sukar dan digeruni kebanyakan pelajar, merangkumi pengetahuan, kemahiran dan nilai yang menuntut pelajarnya berfikir secara analitik dan logik bagi memahami sesuatu konsep matematik. Penyelesaian masalah yang merupakan jantung kepada matematik memerlukan komitmen daripada guru untuk berupaya memindahkan ilmu secara optimum kepada pelajar agar dapat menerima serta menguasai bukan sahaja kefahaman konseptual malahan kefahaman prosedural. Kejayaan proses ini berhubung kait dengan efikasi kendiri kedua-dua pihak guru dan pelajar.

Dalam konteks pendidikan matematik, pelbagai komponen efikasi kendiri diterokai bagi mendapatkan maklumat untuk menangani isu berkaitan matematik. Komponen efikasi kendiri ini terbahagi kepada dua dimensi utama; golongan yang menyampaikan ilmu iaitu guru, dan golongan yang menerima ilmu iaitu pelajar. Pelajar yang merupakan produk akhir dalam sesuatu pelaburan pendidikan, memerlukan perhatian agar dapat membentuk efikasi kendiri yang positif. Sikap dan minat terhadap matematik boleh ditingkatkan melalui efikasi kendiri matematik pelajar. Manakala guru juga berperanan dalam membentuk efikasi kendiri pelajar. Secara tidak langsung, efikasi kendiri pengajaran guru juga perlu diambil perhatian.

Tujuan utama kajian ini dijalankan adalah untuk meneroka dan meninjau aspek-aspek yang berkaitan dengan efikasi kendiri dalam pendidikan matematik khususnya komponen efikasi kendiri dan rangkumannya dalam penyelidikan pendidikan matematik. Justeru itu, sorotan literatur bersistematik ini dijalankan untuk menjawab persoalan-persoalan berikut:

1. Apakah komponen bagi efikasi kendiri dalam penyelidikan empirikal pendidikan matematik?

2. Bagaimana efikasi kendiri dikaji dalam penyelidikan empirikal pendidikan matematik?

\section{Sorotan Literatur}

Efikasi kendiri adalah kepercayaan atau persepsi individu terhadap kebolehannya untuk melaksanakan sesuatu tahap tugasan (Han et al., 2015). Menurut Bandura (1977), efikasi kendiri adalah kepercayaan individu akan kemampuannya untuk berjaya dalam melaksanakan sesuatu perkara atau tugasan dengan berkesan. Secara dasarnya, efikasi kendiri ini merujuk kepada kepercayaan dan keyakinan seseorang individu terhadap keupayaan dalam melakukan sesuatu tugasan mengikut matlamat yang ingin dicapai. 
Efikasi kendiri matematik merupakan keyakinan kendiri individu untuk melengkapkan sesuatu tugasan matematik dengan jayanya (Ferla et al., 2009). Efikasi kendiri akademik pula merujuk kepada penilaian pelajar terhadap keupayaan mereka untuk mengorganisasi dan melakukan tingkah laku pembelajaran bagi mencapai sasaran tahap akademik tertentu (Bandura 1986a, 1997). Menurut Pajares (2006), dua puluh lima peratus daripada kejayaan akademik pelajar adalah berdasarkan kepada efikasi kendiri. Oleh itu, untuk memastikan peningkatan dalam pencapaian akademik pelajar, efikasi kendiri mereka juga perlu ditingkatkan. Pelajar yang mempunyai efikasi kendiri yang tinggi adalah lebih berminat untuk belajar dan tekal dalam menghadapi sebarang masalah (Zimmerman, 2000).

Peranan guru dalam mempengaruhi efikasi kendiri pelajar juga diambil penekanan. Memahami kepercayaan atau persepsi guru mengenai kebolehan mereka adalah penting untuk pembangunan profesional mereka (Pajares, 1992). Efikasi kendiri telah muncul sebagai peramal kejayaan utama dalam pelbagai tugasan termasuk pengajaran (Bandura et al., 1996). Keupayaan guru dalam melaksanakan sesi pengajaran dan pembelajaran (PdP) Matematik dengan berkesan dan bermakna mempunyai kaitan dengan efikasi kendiri matematik dan efikasi pengajaran matematik. Menurut Bandura (1986b), sumber kepada efikasi kendiri adalah pengalaman masteri, pembelajaran vikarius, pemujukan lisan dan keadaan emosi dan fisiologi. Empat sumber tersebut perlu diberi perhatian sewajarnya supaya dapat memberi kesan kepada efikasi kendiri guru dan juga efikasi kendiri pelajar.

\section{Metod Kajian}

Kajian ini dibuat berdasarkan tinjauan literatur bersistematik yang memfokuskan komponen efikasi kendiri dan rangkumannya dalam penyelidikan pendidikan matematik. Terdapat lima fasa (Bakar et al., 2018) yang digunakan dalam kajian ini. Fasa pertama ialah menetapkan soalan sebelum tinjauan literatur dijalankan, seperti kajian ini yang mempunyai dua persoalan kajian. Fasa kedua pula ialah mengenal pasti tugasan yang berkaitan iaitu proses mengenal pasti kajian yang berkaitan dan relevan sebelum tapisan dijalankan mengikut kriteria yang ditetapkan. Fasa ketiga melibatkan proses mentaksirkan kualiti kajian berdasarkan kriteria kajian yang diterima dan ditolak. Fasa keempat ialah membuat rumusan terhadap bukti-bukti yang dikumpulkan dan akhirnya fasa kelima ialah membuat tafsiran terhadap dapatan kajian. Kajian ini menggunakan Model PRISMA yang memberi panduan kepada penulis agar dapat memastikan ketelitian dan kualiti proses kajian (Moher et al., 2009). Terdapat empat peringkat yang terlibat iaitu pengenalpastian, penapisan, penyemakan kelayakan dan pemeriksaan rangkuman. Rajah 1 menunjukkan gambaran keseluruhan berkaitan langkah dan prosedur yang diikuti dalam Model PRISMA bagi menghasilkan sorotan literatur bersistematik.

Terdapat beberapa kriteria yang diterima dan ditolak yang telah ditetapkan. Kriteria yang diterima ialah artikel yang diterbitkan dalam tempoh lima tahun terkini iaitu dari tahun 2016 hingga 2020. Artikel perlu berkaitan efikasi kendiri yang merangkumi semua peringkat pengajian bermula daripada peringkat pra-sekolah hingga peringkat pengajian tinggi. Artikel mestilah kajian empirikal berteks penuh yang telah disemak oleh pewasit dan diterbitkan dalam bahasa Melayu atau bahasa Inggeris. Kriteria yang ditolak adalah termasuk artikel yang diterbitkan sebelum tahun 2016 dan artikel yang bukan kajian empirikal seperti bab dalam buku serta ulasan. Disertasi, tesis dan prosiding juga ditolak. Istilah carian yang digunakan antaranya ialah "Efikasi Kendiri" dan "Efikasi Matematik".

Sebanyak 95 artikel yang diperoleh daripada enjin carian ERIC dengan menggunakan istilah carian yang telah ditetapkan. Terdapat tambahan 57 artikel daripada enjin carian Google Scholar. Setelah diteliti, sebanyak 48 artikel duplikasi dikeluarkan menjadikannya hanya tinggal 104 artikel. Artikel kemudiannya disaring kepada kajian empirikal dan kajian yang bukan dijalankan dalam tempoh yang lama melebihi satu tahun. Daripada jumlah 79 artikel, 27 artikel tidak termasuk dalam fokus analisis. Sebanyak 52 artikel berteks penuh ditaksir dan 32 artikel dikeluarkan kerana tidak menepati kelayakan. Akhirnya sebanyak 20 artikel yang dianalisis bagi mencapai tujuan sorotan literatur sistematik ini dijalankan. 


\section{Rajah 1: Model PRISMA}

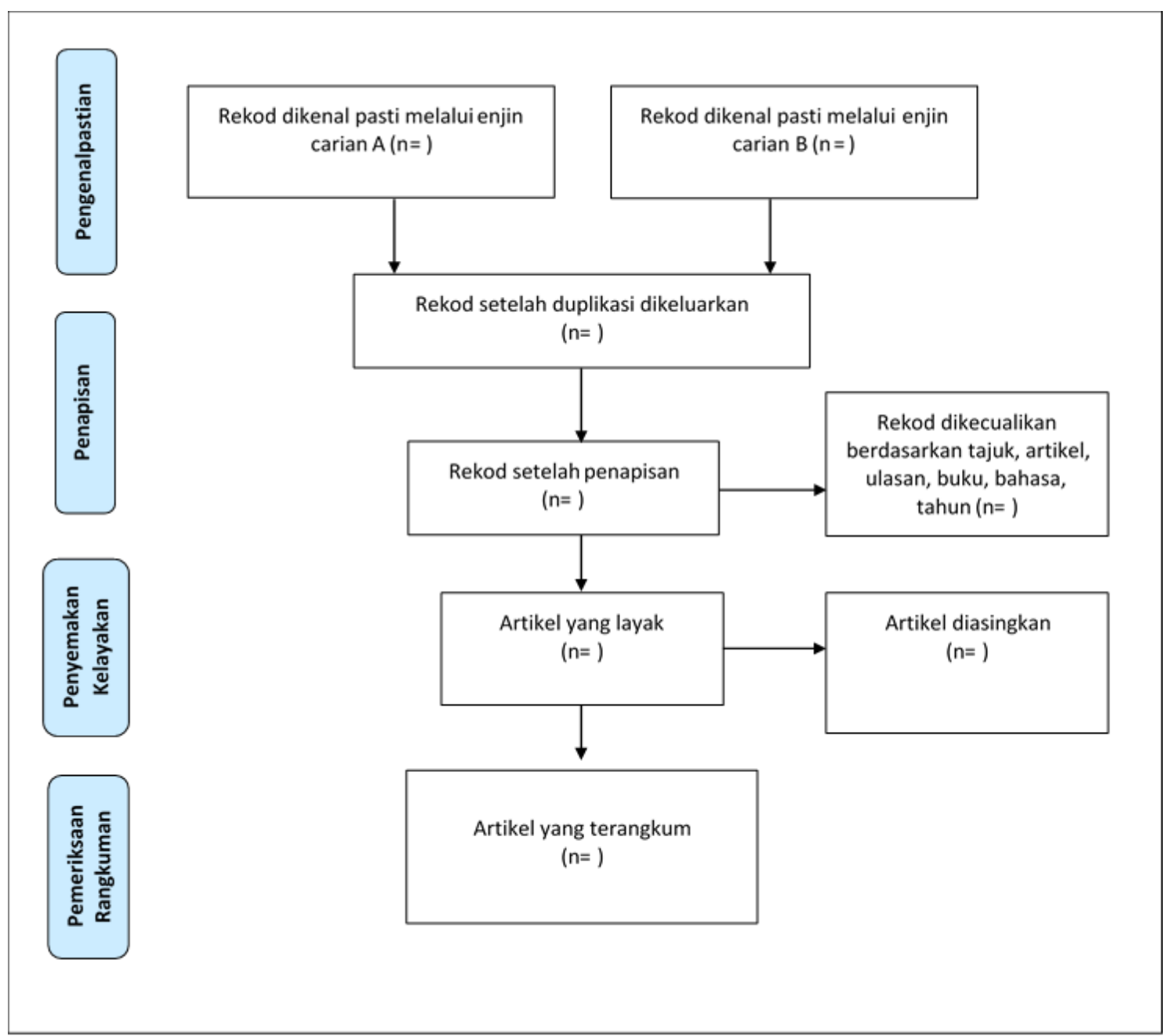

\section{Hasil Kajian}

Dapatan kajian menunjukkan terdapat 4 komponen efikasi kendiri dikategorikan iaitu efikasi kendiri matematik, efikasi kendiri teknologi, efikasi kendiri akademik dan efikasi kendiri pengajaran. Efikasi kendiri matematik merangkumi efikasi kendiri terhadap pengetahuan matematik, kemahiran matematik, pengetahuan-kandungan matematik dan kefasihan fakta matematik (mathematics fact fluency). Efikasi kendiri teknologi pula merangkumi efikasi kendiri terhadap pengintegrasian teknologi dan komputer. Kategori ketiga iaitu efikasi kendiri akademik, adalah berdiri sendiri manakala kategori keempat iaitu efikasi kendiri pengajaran merangkumi efikasi kendiri terhadap strategi pengajaran dan proses pengajaran. Hanya efikasi kendiri matematik melibatkan kajian terhadap guru dan pelajar, manakala efikasi kendiri teknologi, efikasi kendiri akademik dan efikasi kendiri pengajaran melibatkan kajian terhadap guru sahaj. Jadual 1 menunjukkan komponen efikasi kendiri berdasarkan sampel kajian.

Jadual 1: Komponen Efikasi Kendiri

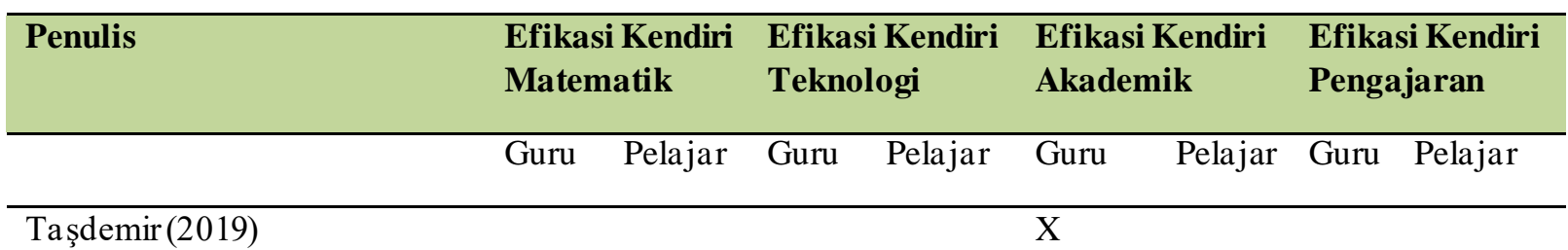


Bakaret al. (2020), Thurm \&

Barzel(2020)

Dinçer \& Yilmaz (2016), Zuya $\quad \mathrm{X}$ et al. (2016), Althauser(2017),

Harun (2017), Peker \& Erol

(2018), Ata soy (2019)

Giles et al. (2016), Rushton et

al. (2016), ÜNSAL et al.

(2016), Zuya et al. (2016),

Ünlü (2018), Cruz et al. (2019),

Dofková (2019),

Kundu \& Ghose (2016), Rahmi

et al. (2017), Recberet al.

(2017), Masitoh \& Fitriy ani

(2018), Ozkal(2019),
$\mathrm{X}$
X

Bagi menjawab persoalan kajian kedua, dapatan kajian bagi analisis horizontal berkaitan (1) negara di mana kajian dilaksanakan, (2) rekabentuk kajian (kaedah yang digunakan dan sampel kajian), (3) garis penyelidikan utama dalam penyelidikan melibatkan efikasi kendiri, dan (4) dapatan kajian utama, dikemukakan.

\section{Negara Kajian}

Jadual 2 menunjukkan 9 buah negara di mana kajian dilaksanakan. Berdasarkan jadual tersebut, dapat diperhatikan majoriti kajian dilaksanakan di benua Asia. Turki menjadi negara tertinggi kajian berkaitan efikasi kendiri dilaksanakan iaitu sebanyak 8 kajian, diikuti dengan Amerika Syarikat sebanyak 4 kajian.

\section{Jadual 2: Negara Kajian}

\begin{tabular}{|c|c|c|}
\hline Negara & $\mathbf{n}$ & Kajian \\
\hline Amerika Syarikat & 4 & $\begin{array}{l}\text { Giles et al. (2016), Rushton et al. (2016), Althauser (2017), } \\
\text { Cruz et al. (2019) }\end{array}$ \\
\hline Cyprus & 1 & Ozkal (2019) \\
\hline India & 1 & Kundu \& Ghose (2016) \\
\hline Indonesia & 2 & Rahmi et al. (2017), Masitoh \& Fitriyani (2018) \\
\hline Jerman & 1 & Thurm \& Barzel (2020) \\
\hline Malaysia & 1 & Bakar et al. (2020) \\
\hline Nigeria & 1 & Zuya et al. (2016) \\
\hline Republik Czech & 1 & (Dofková 2019) \\
\hline Turki & 8 & $\begin{array}{l}\text { ÜNS AL et al. (2016), Dinçer \& Yilmaz (2016), Recber et } \\
\text { al. (2017), Harun (2017), Peker \& Erol (2018), Ünlü } \\
\text { (2018), Taşdemir (2019), Atasoy (2019), }\end{array}$ \\
\hline
\end{tabular}

\section{Reka Bentuk Kajian}

Kaedah bagi setiap kajian yang dianalisis telah dikodkan berdasarkan sampel kajian. Senarai kaedah kajian yang digunakan untuk mengkaji efikasi kendiri adalah: (1) ujian, (2) soal-selidik, (3) temu bual, dan (4) pemerhatian. Jadual 3 menunjukkan reka bentuk dan kaedah kajian yang digunakan berserta bilangan peserta (n) yang terlibat dalam setiap kajian berkaitan.

Jadual 3: Reka Bentuk dan Kaedah Kajian 
DOI: https://doi.org/10.47405/mjssh.v6i1.623

\begin{tabular}{|c|c|c|c|c|c|c|c|c|}
\hline Kajian & n & Kuantitatif & Kualitatif & Gabungan & Ujian & $\begin{array}{l}\text { Soal } \\
\text { selidik }\end{array}$ & Temubual & Pemerhatian \\
\hline $\begin{array}{l}\text { Althauser } \\
(2017)\end{array}$ & 347 & & & $\mathrm{X}$ & & $\mathrm{X}$ & $\mathrm{X}$ & $\mathrm{X}$ \\
\hline Ata soy (2019) & 85 & $X$ & & & $X$ & $X$ & & \\
\hline $\begin{array}{l}\text { Bakaret al. } \\
(2020)\end{array}$ & 66 & $\mathrm{X}$ & & & & $\mathrm{X}$ & & \\
\hline $\begin{array}{l}\text { Cruz et al. } \\
(2019)\end{array}$ & 238 & $\mathrm{X}$ & & & & $\mathrm{X}$ & & \\
\hline $\begin{array}{l}\text { Dinçer \& } \\
\text { Yilmaz (2016) }\end{array}$ & 127 & $\mathrm{X}$ & & & & $\mathrm{X}$ & & \\
\hline $\begin{array}{l}\text { Dofková } \\
\text { (2019) }\end{array}$ & 77 & $X$ & & & & $X$ & & \\
\hline $\begin{array}{l}\text { Giles et al. } \\
\text { (2016) }\end{array}$ & 41 & $\mathrm{X}$ & & & & $X$ & & \\
\hline Harun(2017) & 212 & $X$ & & & & $X$ & & \\
\hline $\begin{array}{l}\text { Kundu \& } \\
\text { Ghose (2016) }\end{array}$ & 784 & $\mathrm{X}$ & & & & $\mathrm{X}$ & & \\
\hline $\begin{array}{l}\text { Masitoh\& } \\
\text { Fitriyani } \\
\text { (2018) }\end{array}$ & 35 & & $\mathrm{X}$ & & $\mathrm{X}$ & $\mathrm{X}$ & $\mathrm{X}$ & $X$ \\
\hline Ozkal(2019) & 651 & $X$ & & & & $X$ & & \\
\hline $\begin{array}{l}\text { Peker \& Erol } \\
(2018)\end{array}$ & 158 & $\mathrm{X}$ & & & & $\mathrm{X}$ & & \\
\hline $\begin{array}{l}\text { Rahmiet al. } \\
\text { (2017) }\end{array}$ & 70 & $\mathrm{X}$ & & & $\mathrm{X}$ & $\mathrm{X}$ & & \\
\hline $\begin{array}{l}\text { Recberet al. } \\
(2017)\end{array}$ & 934 & $\mathrm{X}$ & & & & $\mathrm{X}$ & & \\
\hline $\begin{array}{l}\text { Rushton et al. } \\
\text { (2016) }\end{array}$ & 57 & $X$ & & & $\mathrm{X}$ & $X$ & & \\
\hline $\begin{array}{l}\text { Taşdemir } \\
\text { (2019) }\end{array}$ & 157 & $\mathrm{X}$ & & & & $\mathrm{X}$ & & \\
\hline $\begin{array}{l}\text { Thurm \& } \\
\text { Barzel(2020) }\end{array}$ & 77 & $\mathrm{X}$ & & & & $\mathrm{X}$ & & \\
\hline Ünlü (2018) & 41 & & & $X$ & & $X$ & $\mathrm{X}$ & \\
\hline $\begin{array}{l}\text { ÜNSAL et al. } \\
\text { (2016) }\end{array}$ & 328 & $\mathrm{X}$ & & & & $\mathrm{X}$ & & \\
\hline $\begin{array}{l}\text { Zuya et al. } \\
(2016)\end{array}$ & 49 & $X$ & & & & $\mathrm{X}$ & & \\
\hline
\end{tabular}

\section{Garis Penyelidikan Utama}

Melalui analisis yang komprehensif, kajian berkaitan efikasi kendiri (mengikut komponen) diorganisasikan kepada tiga garis penyelidikan utama iaitu: (1) tahap efikasi kendiri, (2) hubungan antara efikasi kendiri dengan pemboleh ubah lain yang berkaitan, yang mana akan dijelaskan dengan lebih terperinci, dan (3) pembangunan efikasi kendiri. Kesemua tiga garis penyelidikan utama ini diperincikan kepada tiga kumpulan peserta kajian iaitu: (i) guru praperkhidmatan, (ii) guru dalam perkhidmatan, dan (iii) pelajar. Tahap efikasi kendiri seperti dalam garis penyelidikan utama (1) juga termasuk dengan kajian tahap efikasi kendiri berdasarkan jantina, umur dan pengalaman mengajar. Hubungan antara efikasi kendiri dengan pemboleh ubah lain yang berkaitan, seperti yang dinyatakan dalam garis penyelidikan utama (2) membawa maksud: (a) hubungan antara efikasi kendiri dengan mana-mana pemboleh ubah iaitu tahap geometri, pengajaran guru, kompetensi komunikasi, kebimbangan matematik, pencapaian matematik, kecerdasan emosi dan harga diri, dan (b) kesan pemboleh ubah lain iaitu bahan pengajaran terhadap efikasi kendiri. Terdapat beberapa kajian yang menemui garis penyelidikan berbeza secara serentak, maka kajian tersebut 
dinyatakan dalam lebih daripada satu sel. Jadual 4 menunjukkan garis penyelidikan utama dalam kajian efikasi kendiri.

Jadual 4: Garis Penyelidikan Utama

\begin{tabular}{|c|c|c|c|}
\hline $\begin{array}{l}\text { Garis Penyelidikan } \\
\text { Utama }\end{array}$ & Guru Pra-perkhidmatan & $\begin{array}{l}\text { Guru Dalam } \\
\text { Perkhidmatan }\end{array}$ & Pelajar \\
\hline $\begin{array}{l}\text { Tahap Efikasi } \\
\text { Kendiri }\end{array}$ & $\begin{array}{l}\text { Giles et al. (2016), Zuya et } \\
\text { al. (2016), Atasoy (2019), } \\
\text { Dofková (2019), Taşdemir } \\
\text { (2019) }\end{array}$ & $\begin{array}{l}\text { ÜNSAL et al. (2016), } \\
\text { Peker \& Erol (2018), } \\
\text { Bakar et al. (2020) }\end{array}$ & \\
\hline $\begin{array}{l}\text { Hubungan antara } \\
\text { Efikasi Kendiri } \\
\text { dengan Pemboleh } \\
\text { Ubah lain }\end{array}$ & $\begin{array}{l}\text { Dinçer \& Yilmaz (2016), } \\
\text { Rushton et al. (2016), } \\
\text { Zuya et al. (2016), Harun } \\
\text { (2017), Ünlü (2018), } \\
\text { Atasoy (2019), Cruz et al. } \\
\text { (2019) }\end{array}$ & Bakar et al. (2020) & $\begin{array}{l}\text { Kundu \& Ghose } \\
\text { (2016), Rahmi et } \\
\text { al. (2017), Recber } \\
\text { et al. (2017), } \\
\text { Ozkal (2019) }\end{array}$ \\
\hline $\begin{array}{l}\text { Pembangunan } \\
\text { Efikasi Kendiri }\end{array}$ & Althauser (2017) & $\begin{array}{l}\text { Thurm \& Barzel } \\
\text { (2020) }\end{array}$ & $\begin{array}{l}\text { Masitoh \& } \\
\text { Fitriyani (2018) }\end{array}$ \\
\hline
\end{tabular}

\section{Dapatan Kajian Utama}

Secara keseluruhannya bagi garis penyelidikan utama yang pertama - tahap efikasi kendiri, Giles et al. (2016), Zuya et al. (2016), Atasoy (2019), Dofková (2019) dan Taşdemir (2019) menyatakan tahap efikasi kendiri (mengikut komponen) guru pra-perkhidmatan adalah melebihi purata skor min, tinggi juga positif. ÜNSAL et al. (2016), Peker \& Erol (2018) dan Bakar et al. (2020) turut menyatakan perkara yang sama bagi guru dalam perkhidmatan. Jadual 5 menunjukkan dapatan kajian tersebut.

Jadual 5: Tahap Efikasi Kendiri Guru Pra-perkhidmatan dan Guru Dalam Perkhidmatan

\begin{tabular}{lll}
\hline Tahap Efikasi Kendiri & Guru Pra-perkhidmatan & Guru Dalam Perkhidmatan \\
\hline Melebihi purata skor min & Giles et al. (2016), Zuya et al. & ÜNSAL et al. (2016), Peker \& \\
Tinggi & (2016), Atasoy (2019), & Erol (2018), Bakar et al. \\
Positif & Dofková (2019), Taşdemir & (2020) \\
& $(2019)$ & \\
\hline
\end{tabular}

Tidak terdapat perbezaan yang signifikan bagi tahap efikasi kendiri guru pra-perkhidmatan berdasarkan jantina tetapi terdapat perbezaan berdasarkan umur (Taşdemir 2019). Tidak terdapat perbezaan yang signifikan bagi tahap efikasi kendiri guru dalam perkhidmatan berdasarkan latar belakang pendidikan dan jenis sekolah, tetapi terdapat perbezaan berdasarkan jantina, tahun perkhidmatan dan tahap sekolah (ÜNSAL et al. 2016), yang mana bertentangan dengan Bakar (et al. 2020) yang menyatakan tidak terdapat perbezaan yang signifikan berdasarkan jantina dan pengalaman mengajar. Peker \& Erol (2018) menyatakan tahap efikasi kendiri bagi sub-faktor penglibatan pelajar adalah agak efisien.

Dapatan bagi garis penyelidikan utama yang kedua - hubungan antara efikasi kendiri dengan pemboleh ubah lain yang berkaitan - ditunjukkan seperti dalam jadual 6. Menurut Dinçer \& Yilmaz (2016), Rushton et al. (2016), Harun (2017) dan (Cruz et al. 2019), hubungan antara efikasi kendiri dengan pemboleh ubah yang dikaji bagi guru pra-perkhidmatan adalah tinggi/ kuat, berbanding Zuya et al. (2016) dan Atasoy (2019) yang menyatakan hubungan yang sederhana dan rendah/ lemah masingmasing. Bakar et al. (2020) menyatakan hubungan antara efikasi kendiri dengan pemboleh ubah yang dikaji bagi guru dalam perkhidmatan adalah tinggi/ kuat. Hubungan antara efikasi kendiri pelajar dengan pemboleh ubah yang dikaji adalah tinggi/ kuat (Kundu \& Ghose 2016) dan (Recber et al. 2017), berbanding dengan yang dinyatakan sebagai sederhana oleh Rahmi et al. (2017). Kesan 
DOI: https://doi.org/10.47405/mjssh.v6i1.623

pemboleh ubah lain yang dikaji terhadap efikasi kendiri guru pra-perkhidmatan didapati positif (Ünlü 2018), seperti kesan pemboleh ubah lain terhadap efikasi kendiri pelajar yang juga didapati positif (Ozkal 2019).

Jadual 6: Hubungan antara Efikasi Kendiri dengan Pemboleh Ubah lain

\begin{tabular}{llll}
\hline $\begin{array}{l}\text { Hubungan antara Efikasi } \\
\text { Kendiri dengan Pemboleh } \\
\text { Ubah lain }\end{array}$ & $\begin{array}{l}\text { Guru Pra- } \\
\text { perkhidmatan }\end{array}$ & $\begin{array}{l}\text { Guru Dalam } \\
\text { Perkhidmatan }\end{array}$ & Pelajar \\
\hline $\begin{array}{l}\text { Hubungan antara efikasi } \\
\text { kendiri dengan mana-mana } \\
\text { pemboleh ubah } \\
\text { Tinggi/ kuat }\end{array}$ & $\begin{array}{l}\text { Dinçer \& Yilmaz } \\
\text { (2016), Rushton et al. } \\
\text { (2016), Harun (2017), } \\
\text { (Cruz et al. 2019) }\end{array}$ & $\begin{array}{l}\text { Bakar et al. } \\
(2020)\end{array}$ & $\begin{array}{l}\text { Kundu \& Ghose } \\
\text { (2016), Recber et } \\
\text { al. (2017) }\end{array}$ \\
$\begin{array}{l}\text { Zuya et al. (2016) } \\
\text { Atasoy (2019) }\end{array}$ & Rahmi et al. (2017) \\
$\begin{array}{l}\text { Rendah/ lemah } \\
\text { Kesan pemboleh ubah lain } \\
\begin{array}{l}\text { Positif } \\
\text { Negatif }\end{array}\end{array}$ & Ünlü (2018) & Ozkal (2019) \\
\hline
\end{tabular}

Bagi garis penyelidikan utama yang ketiga - pembangunan efikasi kendiri -, dapatan kajian diperincikan seperti dalam jadual 7. Althauser (2017), Thurm \& Barzel (2020) dan Masitoh \& Fitriyani (2018) masing- masing menyatakan bahawa terdapat peningkatan yang positif bagi pembangunan efikasi kendiri guru pra-perkhidmatan, guru dalam perkhidmatan dan pelajar. Pendekatan pengajaran yang digunakan seperti pengajaran mikro, penggunaan bahan teknologi dan pembelajaran berasaskan masalah terbukti dapat meningkatkan efikasi kendiri bagi ketiga-tiga kumpulan peserta kajian tersebut. Dapatan ini menyokong pernyataan Bandura (1986b) iaitu sumber kepada efikasi kendiri adalah pengalaman masteri, pembelajaran vikarius, pemujukan lisan dan keadaan emosi dan fisiologi. Penggunaan bahan pengajaran yang bersesuaian dapat meningkatkan efikasi kendiri guru dan juga pelajar.

Jadual 7: Pembangunan Efikasi Kendiri

\begin{tabular}{llll}
\hline $\begin{array}{l}\text { Pembangunan } \\
\text { Efikasi Kendiri }\end{array}$ & $\begin{array}{l}\text { Guru Pra- } \\
\text { perkhidmatan }\end{array}$ & $\begin{array}{l}\text { Guru Dalam } \\
\text { Perkhidmatan }\end{array}$ & Pelajar \\
\hline Peningkatan & Althauser (2017) & $\begin{array}{l}\text { Thurm \& Barzel } \\
(2020)\end{array}$ & $\begin{array}{l}\text { Masitoh \& Fitriyani } \\
(2018)\end{array}$ \\
\hline
\end{tabular}

\section{Perbincangan Kajian}

Analisis daripada sorotan literatur bersistematik mendapati bahawa masih banyak kajian berkaitan efikasi kendiri dalam konteks pendidikan matematik dijalankan. Skop kajian tidak hanya bertumpu kepada efikasi kendiri matematik sahaja, malahan skop yang lebih luas seperti efikasi kendiri pengajaran matematik diterokai selari dengan perkembangan pendidikan dunia. Sampel/responden juga merangkumi pelajar, guru pra-perkhidmatan dan guru dalam perkhidmatan. Kajian yang dijalankan ada yang berskala besar, yang mana dapat meningkatkan kejituan dan kepentingan dapatan kajian. Walaupun majoriti kajian dibuat di benua Asia, namun sangat sedikit kajian yang dijalankan di Asia Tenggara termasuk di Malaysia. Kesemua kajian efikasi kendiri (mengikut komponen) yang mengkaji tahap efikasi kendiri menunjukkan tahap efikasi kendiri yang melebihi purata skor min/ tinggi/ positif. Hampir keseluruhan dapatan kajian yang berkaitan menunjukkan hubungan yang positif (sederhana dan tinggi/ kuat) antara efikasi kendiri dengan pemboleh ubah lain yang dikaji, serta kesan yang positif 
terhadap efikasi kendiri. Kesemua kajian yang melibatkan pembangunan efikasi kendiri turut melaporkan perkembangan positif dengan penggunaan pendekatan pengajaran yang bersesuaian.

\section{Kesimpulan}

Untuk menangani isu efikasi kendiri berkaitan matematik, hasil analisis kajian ini diharap dapat memberikan maklumat tentang keperluan penyelidikan bagi mengenal pasti elemen-elemen pendidikan matematik yang boleh diperbaiki dan ditingkatkan. Penekanan terhadap efikasi kendiri dalam kalangan guru adalah sangat penting dan utama bagi mempengaruhi efikasi kendiri pelajar supaya lebih positif. Perkara ini bukan sahaja dapat meningkatkan kompetensi dan profesionalisme guru, malah secara langsung dapat membentuk generasi yang holistik dalam aspek pengetahuan, kemahiran dan nilai yang diperlukan untuk bersaing dalam pasaran global. Hasil analisis ini diharap dapat menyalurkan maklumat yang dikehendaki kepada individu dan pihak berkepentingan seperti sekolah, Pejabat Pelajaran Daerah, Jabatan Pendidikan Negeri, Kementerian Pendidikan Malaysia malah pihak swasta bagi merangka dan merancang pelan tindakan sewajarnya. Kajian yang lebih lanjut boleh dijalankan dengan memfokuskan kepada suatu komponen utama efikasi kendiri dalam konteks pendidikan di Malaysia.

\section{Rujukan}

Althauser, K. L. (2017). The Emphasis of Inquiry Instructional Strategies: Impact on Preservice Teachers' Mathematics Efficacy. Journal of Education and Learning. doi:10.5539/jel.v7n1p53

Atasoy, E. (2019). Elementary Mathematics Teacher Candidates' Geometric Thinking Levels and Their Self-Efficacy in Geometry. Acta Didactica Napocensia. doi:10.24193/adn.12.2.12

Bakar, N. S. A., Maat, S. M. \& Rosli, R. (2020). Mathematics teacher's self-efficacy of technology integration and technological pedagogical content knowledge. Journal on Mathematics Education. doi:10.22342/jme.11.2.10818.259-276

Bakar, N. S. A., Maat, S. M., \& Rosli, R. (2018). A Systematic Review of Teacher's Self-efficacy and Technology Integration. International Journal of Academic Research in Business and Social Sciences. 8(8), 540-557

Bandura, A. (1977). Self-efficacy: Toward a unifying theory of behavioral change. Psychological Review. doi:10.1037/0033-295X.84.2.191

Bandura, A. (1986a). Social foundations of thought and action: Social cognitive theory. Englewood Cliffs, New Jersey: Prentice Hall.

Bandura, A. (1986b). The Explanatory and Predictive Scope of Self-Efficacy Theory. Journal of Social and Clinical Psychology. doi:10.1521/jscp.1986.4.3.359

Bandura, A. (1997). Self-Efficay: The Excercise of Control. Springer Reference.

Bandura, A., Barbaranelli, C., Caprara, G. V. \& Pastorelli, C. (1996). Bandura A, Barbaranelli C, Caprara GV \& Pastorelli C (1996) - Multifaceted Impact of Self-Efficacy Beliefs on Academic Functioning.pdf. Child Development. doi:10.1111/j.1467-8624.1996.tb01791.x

Cruz, J. M., Wilson, A. T. \& Wang, X. (2019). Connections between pre-service teachers' mathematical dispositions and self-efficacy for teaching mathematics. International Journal of Research in Education and Science.

Dinçer, B. \& Yilmaz, S. (2016). An investigation into the perceptions of mathematics and information literacy self-efficacy levels of pre-service primary mathematics teachers. European Journal of Contemporary Education. doi:10.13187/ejced.2016.15.84

Dofková, R. (2019). Evaluation of self-efficacy in prospective primary school teachers in the context of mathematics teaching. Problems of Education in the 21 st Century. doi:10.33225/pec/19.77.244

Ferla, J., Valcke, M. \& Cai, Y. (2009). Academic self-efficacy and academic self-concept: Reconsidering structural relationships. Learning and Individual Differences. doi:10.1016/j.lindif.2009.05.004

Giles, R. M. M., Byrd, K. O. \& Bendolph, A. (2016). An investigation of elementary preservice teachers' self-efficacy for teaching mathematics. Cogent Education. doi:10.1080/2331186X.2016.1160523 
Han, S., Liou-Mark, J., Yu, K. T. \& Zeng, S. (2015). Self-efficacy and Attitudes Towards Mathematics of Undergraduates: A U.S. and Taiwan Comparison. Journal of Mathematics Education () Education for All Spring.

Harun, Ş. (2017). Emotional intelligence and self-esteem as predictors of teacher self-efficacy. Educational Research and Reviews. doi:10.5897/err2017.3385

Kundu, A. \& Ghose, A. (2016). The relationship between attitude and self efficacy in mathematics among higher secondary students. IOSR Journal Of Humanities And Social Science (IOSR-JHSS). doi: $10.9790 / 0837-2104052531$

Masitoh, L F. \& Fitriyani, H. (2018). Improving students' mathematics self-efficacy through problem based learning. Malikussaleh Journal of Mathematics Learning (MJML) 1(1): 26. doi:10.29103/mjml.v1i1.679

Moher, D., Liberati, A., Tetzlaff, J., Altman, D.G., The PRISMA Group (2009). Preferred Reporting Items for Systematic Reviews and Meta-Analyses: The PRISMA Statement. PLoS Med 6(7): e1000097. doi:10.1371/journal.pmed1000097

Ozkal, N. (2019). Relationships between self-efficacy beliefs, engagement and academic performance in math lessons. Cypriot Journal of Educational Sciences. doi:10.18844/cjes.v14i2.3766

Pajares, F. (2006). Self-efficacy during childhood and adolescence: Implication for teacher and adolescence. Self-Efficacy Beliefs of Adolescents.

Pajares, M. F. (1992). Teachers' Beliefs and Educational Research: Cleaning Up a Messy Construct. Review of Educational Research. doi:10.3102/00346543062003307

Peker, M. \& Erol, R. (2018). Investigation of the Teacher Self-Efficacy Beliefs of Math Teachers. Malaysian Online Journal of Educational Sciences.

Rahmi, S., Nadia, R., Hasibah, B. \& Hidayat, W. (2017). The Relation Between Self-Efficacy Toward Math With The Math Communication Competence. Infinity Journal. doi:10.22460/infinity.v6i2.p177-182

Recber, S., Isiksal, M. \& Koc, Y. (2017). Investigating Self-Efficacy, Anxiety, Attitudes and Mathematics Achievement Regarding Gender and School Type. Anales de Psicología. doi:10.6018/analesps.34.1.229571

Rushton, S., Hadley, K. \& Stewart, P. (2016). Mathematics Fluency and Teaching Self-Efficacy of Teacher Candidates. Journal of the International Society for Teacher Education.

Taşdemir, C. (2019). An Investigation of Academic Self-Efficacy Perceptions of Primary Mathematics Teacher Candidates. Higher Education Studies. doi:10.5539/hes.v9n2p72

Thurm, D. \& Barzel, B. (2020). Effects of a professional development program for teaching mathematics with technology on teachers' beliefs, self-efficacy and practices. ZDM Mathematics Education. doi:10.1007/s11858-020-01158-6

Ünlü, M. (2018). Effect of micro-teaching practices with concrete models on pre-service mathematics teachers' self-efficacy beliefs about using concrete models. Universal Journal of Educational Research. doi:10.13189/ujer.2018.060106

ÜNSAL, S., Korkmaz, F. \& PERÇİN, S. (2016). Analysis of Mathematics Teachers' Self-Efficacy Levels Concerning the Teaching Process. Analysis.

Zimmerman, B. J. (2000). Self-Efficacy: An Essential Motive to Learn. Contemporary Educational Psychology. doi:10.1006/ceps.1999.1016

Zuya, H. E., Kwalat, S. K. \& Attah, B. G. (2016). Pre-Service Teachers' Mathematics Self-Efficacy and Mathematics Teaching Self-Efficacy. Journal of Education and Practice. 